\title{
The element-phase composition and properties of the surface layers of carbide-tipped tools made of TK and WC-Co alloys
}

\author{
A. G. Sokolov, E. E. Bobylyov ${ }^{\dagger}$ \\ †ebobylev@mail.ru \\ Kuban State Technological University, 2 Moskovskaya st., 350000, Krasnodar, Russia
}

\begin{abstract}
A technology for the deposition of diffusion titanium coatings from liquid metal media on hard alloys of TK (WC+TiC+Co) and VK (WC+Co) systems is described. It is shown that the diffusion saturation of hard alloy tools of these types by titanium from the $\mathrm{Pb}$-Bi-Li melt in a temperature range $1000-1100^{\circ} \mathrm{C}$ and subsequent heat treatment results in a seven-fold increase of the wear resistance of the tools due to the formation of a diffusion coating. The thickness of the coatings varies depending on the temperature and deposition time and ranges from 2.6 to $6 \mu \mathrm{m}$ on TK alloys and from 2 to $5.4 \mu \mathrm{m}$ on VK alloys. The coatings consist of two layers, the surface one and transition one. The results of elemental and metallographic analyses are presented. The microhardness of a coating on hard alloy T15K6 is about $30000 \mathrm{MPa}$ and on the hard alloy WC-8Co is $25000 \mathrm{MPa}$. The high microhardness of the coatings is caused by their formation on the basis of titanium carbide TiC, while other elements are driven depthward the material to coat. It has been found that the elemental composition of the coatings depends on the composition of the hard alloy under coating. The concentration of titanium in the surface layer of the tool amounts $87.6 \%$ for VK alloys and $93 \%$ for TK alloys. The transition layer is characterized by approximately equal concentrations of titanium and tungsten (about 20 to $25 \%$ ) and a reduced microhardness. The diffusion coatings are characterized by a smooth change of the concentration of elements with depth and good adhesion to the base material.
\end{abstract}

Keywords: carbide-tipped tool, diffusion coating, titanium carbide, elemental composition.

\section{Элементно-фазовый состав и свойства диффузионных титановых покрытий на режущем твердосплавном инструменте типа ТК и ВК}

\author{
Соколов А. Г., Бобылёв Э.Э.† \\ †ebobylev@mail.ru
}

Кубанский государственный технологический университет, ул. Московская 2, 350000, Краснодар, Россия

\begin{abstract}
Описана технология нанесения диффузионных титановых покрытий из среды легкоплавких жидкометаллических растворов на твердые сплавы типа ТК и ВК. Показано, что при диффузионном насыщении твердосплавного инструмента типа ТК и ВК титаном из расплава $\mathrm{Pb}-\mathrm{Bi}-\mathrm{Li}$ в диапазоне температур $1000-1100^{\circ} \mathrm{C}$ и последующей его термической обработке, износостойкость инструмента увеличивается до 7 раз за счет формирования на его поверхности диффузионного покрытия. Толщина покрытия варьируется в зависимости от температуры и времени выдержки, и составляет от 2,6 до 6 мкм на сплавах типа ТК; от 2 до 5,4 мкм на сплавах типа ВК. При этом выявлено, что покрытия состоят из двух слоев - поверхностного и переходного. Приведены результаты элементного и металлографического анализов. Микротвердость покрытия на твердом сплаве Т15К6 составляет до 30000 МПа, на сплаве ВК8 до 25000 МПа. Высокая микротвердость покрытия обеспечивается его формированием на базе карбида титана ТіС, при этом, остальные элементы оттесняются вглубь покрываемого материала. Выявлено, что элементный состав покрытия зависит от состава твердого сплава, на который оно наносится. Концентрация титана в поверхностном слое инструмента составляет 87,6\% для сплавов типа ВК и 93\% для сплавов типа ТК. Переходный слой характеризуется примерно равной концентрацией титана и вольфрама на уровне 20 - 25\%, а также снижением микротвердости. Полученные диффузионные покрытия характеризуются плавным изменением концентрации элементов по толщине и высокой степенью адгезии с материалом-основой.
\end{abstract}

Ключевые слова: режущий твердосплавной инструмент, диффузионные покрытия, карбид титана, элементный состав. 


\section{1. Введение}

В процессе механической обработки материалов резанием, наибольшую нагрузку испытывает режущая кромка инструмента, при этом происходит её интенсивное изнашивание. Интенсивность изнашивания во многом зависит от применяемых инструментальных материалов. В настоящее время наибольшее распространение в промышленности имеют вольфрамокобальтовые и титан-вольфрамокобальтовые твердые сплавы. Широкое распространение данные инструментальные материалы получили благодаря таким свойствам, как высокая твердость, износостойкость и теплостойкость. Однако, при обработки современных материалов, обладающих высокими прочностными свойствами, вязкостью разрушения, а также при использовании современные автоматизированных методов обработки, возрастают требования к эксплуатационными свойствами режущего инструмента, в частности, к его стойкости, к стабильности его геометрии. Вследствие не высокой износостойкости, стойкости к адгезионному схватыванию традиционный твердосплавный инструмент не может обеспечить режущему инструменту требуемых эксплуатационных свойств. Значительное повышение эксплуатационных свойств твердосплавного режущего инструмента может быть достигнуто путем нанесения на его рабочие поверхности износостойких покрытий.

Наиболее эффективными методами нанесения покрытий на режущий инструмент являются: метод химического осаждения покрытий - CVD (Chemical Vapor Deposition), метод физического осаждения покрытий PVD (Physical Vapor Deposition), а также химико-термическая обработка - ХTO, в частности, технология диффузионной металлизации из среды легкоплавких жидкометаллических растворов [1,2].

Метод химического осаждения покрытий, CVD (Chemical Vapor Deposition) основан на получении различного рода покрытий вследствие гетерогенных химических реакций в парогазовой среде, окружающей покрываемый инструмент. Основной элемент покрытия восстанавливается из галогенидов металла водородом, в присутствии других компонентов газовой смеси (аммиак, окись углерода и т.д.). Наибольшее распространение при использовании CVD нашли следующие соединения: $\mathrm{TiC}, \mathrm{TiCN}, \mathrm{TiN}, \mathrm{Al}_{2} \mathrm{O}_{3}$. Общими недостатками CVD технологий являются сложность оборудования, необходимость использования ядовитых и взрывоопасных газов и соединений $[1,2]$.

Метод физического осаждения покрытий, PVD (Physical Vapor Deposition), основан на осаждении c предварительной ионизацией элементов покрытия в парообразном агрегатном состоянии на твердой подложке. Недостатками технологий формирования PVD являются: сложность технологического оборудования, требующая использования вакуумной техники, ограниченная по форме номенклатура покрываемых изделий, малая толщина покрытий и необходимость нанесения многослойных покрытий $[1,2]$.

Одним из самых распространенных методов улучшения эксплуатационных характеристик режущего инструмента является химико-термическая обработка (XTO). Сущность ХTO заключается в нагреве и выдержке при заданной температуре изделий в активных твердых, жидких, или газовых средах, в результате чего, вследствие диффузионных процессов, в поверхностных слоях изделий изменяется элементный и структурно-фазовый состав, а, следовательно, и свойства этих поверхностных слоев (поверхностное легирование) [1,2].

Среди методов ХТО наибольшее распространение получили: цементация, азотирование, нитроцементация, цианирование, алитирование, борирование и т.д. Наиболее эффективной технологией ХТО применительно к твердым сплавам является разработанный нами способ диффузионной металлизации из среды легкоплавких жидкометаллических растворов $[1,2]$.

Процесс диффузионной металлизации из среды легкоплавких жидкометаллических растворов основан на явлении изотермического, селективного переноса элементов покрытия, растворенных в легкоплавком расплаве, на поверхность изделия с последующим диффузионным взаимодействием элементов покрытия с основным материалом изделия $[1,3,5,8]$.

Суть технологии заключается в том, что изделия погружаются в расплав легкоплавкого металлического элемента, в котором в определенной пропорции растворены элементы покрытий. Изделия выдерживаются в расплаве при заданных температурах от 10 минут до 5 часов. За это время элементы покрытий диффундируют в поверхностный слой изделия, легируют их, образуя диффузионное покрытие $[1,8]$.

Технология диффузионной металлизации из среды легкоплавких жидкометаллических растворов обладает рядом преимуществ по сравнению с аналогичными технологиями, обеспечивающими формирование функциональных покрытий на твердых сплавах, среди которых:

- использование менее энергозатратного оборудования;

- возможность получения как однокомпонентных, так и многокомпонентных покрытий;

- возможность наносить покрытия на изделия сложной конфигурации, а также тонкостенные изделия;

- высокая степень адгезии покрытия с материаломосновой;

- возможность применения технологии для конструкционных, инструментальных сталей и твердых сплавов марок ВК, ТК, ТТК.

C точки зрения повышения эксплуатационных свойств режущего инструмента методом диффузионной металлизации из среды легкоплавких жидкометаллических растворов, наибольший интерес представляют покрытия на основе карбида титана ТiC. Нанесение титановых покрытий на твердосплавный инструмент состоит из двух этапов: кратковременная высокотемпературная цементация и нанесение титанового покрытия. Цементация проводится с целью обеспечения формирования покрытия за счет углерода, полученного в ходе предварительной цементации, а не за счет углерода материала основы. При этом, твердость покрытия зависит от количества карбида титана, образующегося при его нанесении [3]. 
Целью данной статьи является определение влияния диффузионного насыщения твердых сплавов типа ТК и ВК титаном из среды легкоплавких жидкометаллических растворов на элементный, фазовый составы, свойства их поверхностных слоев и на эксплуатационные свойства режущего инструмента.

\section{2. Методика}

Диффузионные титановые покрытия наносились на исходно не покрытые пятигранные пластины PNUM-110408 из сплавов ВК8, Т15К6.

Покрытие наносилось путем диффузионной металлизации с применением разработанной нами технологии [4] путем погружения твердосплавных пластин в ампулу с легкоплавким расплавом и их выдержки в изотермическом режиме в среде инертных газов. В качестве легкоплавкого расплава, осуществляющего доставку элемента к поверхности покрываемого изделия, использовался расплав эвтектического состава свинец-висмут-литий, в который в заданном количестве вводился титан.

Процесс диффузионной металлизации из среды легкоплавких жидкометаллических растворов основан на явлении изотермического, селективного переноса элементов покрытия, растворенных в легкоплавком расплаве, на поверхность изделия с последующим диффузионным взаимодействием элементов покрытия с основным материалом изделия [5].

Суть технологии заключается в том, что изделия погружаются в расплав легкоплавкого металлического элемента, в котором в определенной пропорции растворены элементы покрытий. Изделия выдерживаются в расплаве при заданных температурах от 10 минут до 5 часов. За это время элементы покрытий диффундируют в поверхностный слой изделия, легируют их, образуя диффузионное покрытие [5].

Перед нанесением покрытия пластины были подвергнуты кратковременной высокотемпературной цементации. Цементация служит для насыщения поверхности инструмента углеродом, за счет которого впоследствии формируется покрытие. Цементация проводилась с применением технологии вакуумной цементации в среде пропан-бутановой смеси в вакуумной печи BMI BMICRO. Пластины подвергались цементации при температуре $1000^{\circ} \mathrm{C}$, длительностью 60 минут. Толщина цементованного слоя составляет 3-4 мкм. Исследование влияния предварительной высокотемпературной цементации на свойства твердосплавных пластин, имеющих диффузионные титановые покрытия, описывается в предыдущих работах $[3,10]$.

После нанесения покрытия, пластины были подвергнуты старению при температуре $500-800^{\circ} \mathrm{C}$ по разработанной и запатентованной нами технологии. Старение проводилось с целью перераспределения углерода по покрытию и выделения второй дисперсной фазы в виде карбида титана.

Процесс нанесения покрытия проводился в разработанной, запатентованной и изготовленной нами установки для диффузионной металлизации в среде легкоплавких жидкометаллических растворов [6]. Дан- ная установка обеспечивает возможность нанесения покрытий в открытой жидкометаллической ванне в циклическом режиме и совмещать процесс диффузионной металлизации с термической обработкой материала покрываемого изделия.

Твердость пластин проверялась по методу Роквелла и методу микро-Виккерса. Металлографические исследования проводились на прямых и косых микрошлифах. Исследования по определению микротвердости покрытий проводились на микротвердомере ПМТ-3.

Состав покрытий и переходной зоны исследовались методом рентгеноспектрального микроанализа. При этом использовался растровый электронный микроскоп JEOL JSM-7500F и спектрометр INCA x-sight oxford instruments. Спектрометр рентгеновский с энергетической дисперсией INCA x-sight предназначен для измерений зависимости интенсивности рентгеновского излучения от длины волны (энергии кванта) в составе растровых электронных микроскопов и электроннозондовых микроанализаторов.

Период стойкости инструмента определялся при точении прутков диаметром 50 мм, изготовленных из стали У10 после закалки и среднего отпуска, твердостью 43...45HRC.

Токарная обработка проводилась при скорости резания 130 м/мин, с подачей 0,8 мм/об, глубиной резания 1 мм. За период стойкости принималось время, за которое инструмент терял режущие свойства.

\section{3. Результаты и обсуждение}

\section{1. Металлографический и элементно-фазо- вый анализ}

В результате исследований установлено, что диффузионное насыщение твердых сплавов титаном из расплава свинец-висмут-литий, приводит к формированию на их поверхности покрытий величиной 4-6 мкм.

Диффузионные титановые покрытия состоят из двух слоев: само покрытие и переходный слой между покрытием и покрываемым материалом. Элементный состав покрытий образцов, показавших наибольшую стойкость при точении, представлен на рис. 1.

Как следует из анализа результатов микрорентгеноспектрального анализа, наружный слой покрытия содержит в основном титан (рис. 2, 3). При этом, микротвердость наружного слоя составляет 30000 МПа для покрытий на сплаве Т15К6 и 24750 Мпа для сплава ВК8 (рис. 4). На основании этого можно сделать вывод о том, что титан в покрытии находится в связанном состоянии в виде карбидов титана $\mathrm{TiC}$, имеющего микротвердость 31500 МПа [7]. Также, данный факт подтверждается проведенными ранее исследованиями относительно нанесения диффузионных титановых покрытий из среды легкоплавких жидкометаллических растворов на стали $[5,8]$. Концентрация карбида титана $\mathrm{TiC}$ в покрытии составляет $87,6 \%$ и изменяется от $87,6 \%$ до $1,8 \%$ на глубине 35 мкм для сплавов группы ВК. Для сплавов группы ТК концентрация карбидов титана в покрытии составляет 93\%, плавно уменьша- 
ясь и до 15\% на глубине 30 мкм. При этом, содержание углерода составляет 7\% (масс.), концентрация которого уменьшается на глубине 30 мкм, и составляет 4\% для сплавов группы ВК и 6\% для сплавов группы ТК. При таком содержании углерода возможно образование неустойчивых, не стехиометрических карбидов титана. Однако за счет достаточно длительного термического воздействия, происходящего в процессе диффузионного насыщения, происходит образование карбидов титана $\mathrm{TiC}$ так как данный карбид имеет по сравнению с не стехиометрическими карбидами имеет более низкую свободную энергию образования карбида (44400 кал/моль) [8].

Кроме карбидной фазы в покрытии присутствуют элементы, входящие в состав основы - кобальт и вольфрам. При этом, в покрытии концентрация данных элементов увеличивается по мере приближения к переходной зоне. В переходной зоне покрытия на сплаве Т15К6 замечен рост концентрации вольфрама до 23,2\%, кобальта до 5,3\% на глубине 20 мкм. При переходе к основе концентрация титана снижается до $15 \%$. В переходной зоне покрытия на сплаве ВК8 рост концентрации вольфрама составляет $41 \%$, кобальта $6 \%$.

Переходная зона покрытий характеризуется снижением концентрации титана и ростом концентрации вольфрама, что влечет за собой падение микротвердости (рис. 5).

Переходная зона покрытий на сплавах группы ВК характеризуется равным содержанием титана и вольфрама на глубине 32 мкм, при этом, их концентрация составляет $45 \%$ (рис. 3,4 ). На глубине 35 мкм происходит постепенное снижение концентрации титана до 1,8\% при увеличении концентрации вольфрама до $87,2 \%$. Далее происходит уменьшение концентрации титана, на глубине 40 мкм титан не был обнаружен, концентрация вольфрама увеличивается до 89\%. Кроме этого, в переходной зоне начинается постепенное увеличение концентрации кобальта до 6\% на глубине 30 мкм и рост концентрации до 7\% на глубине свыше 35 мкм. В самом покрытии кобальт не присутствует, что хорошо видно на спектрограмме Со (рис. 6).

На сплавах группы ТК наблюдается равная концентрация титана и вольфрама в переходной зоне на глубине 24 мкм, которая составляет 42\%. На глубине свыше 30 мкм концентрация элементов соответствует материалу без покрытия, при этом наблюдается плавное снижение концентрации титана и повышение концентрации вольфрама. В самом покрытии практически отсутствует кобальт, при этом, данный элемент оттесняется в переходную зону, что хорошо просматривается на спектрограмме Со (рис. 4).

Весь углерод в покрытии находится в связанном состоянии в виде карбидов титана (ТiC) и карбидов вольфрама (WC). Также, при насыщении поверхности твердосплавных пластин титаном наблюдается оттеснение кобальта вглубь покрытия. Данный эффект объясняется тем, что карбид титана $\mathrm{TiC}$ имеет низкую растворимость в кобальте, при $700^{\circ} \mathrm{C}$ порядка $0,08-0,15 \%$.

Таким образом, покрытия, получаемые диффузионным титанированием из среды легкоплавких жид-

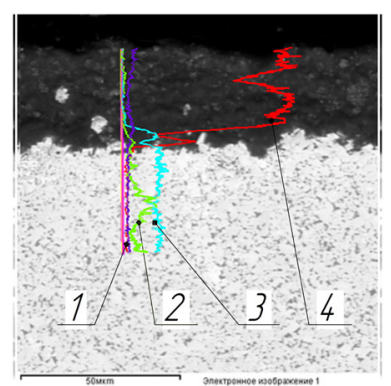

$1-\mathrm{C}, 2-\mathrm{Co}, 3-\mathrm{W}, 4-\mathrm{Ti}$

a

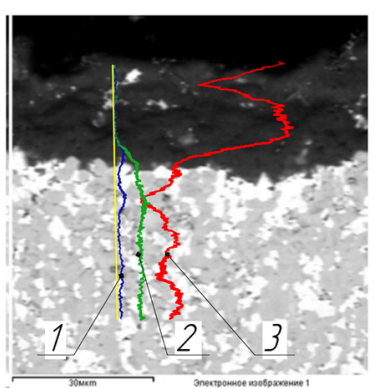

$1-\mathrm{Co}, 2-\mathrm{W}, 3-\mathrm{Ti}$

$\mathrm{b}$
Pис. 1. (Color online) Характер распределения элементов в покрытии, формирующимся на твердых сплавах: (a) ВК8 температура нанесения покрытия $1100^{\circ} \mathrm{C}$, длительностью 1 час, (b) Т15К6 температура нанесения покрытия $1000^{\circ} \mathrm{C}$, длительностью 30 мин.

Fig. 1. (Color online) The concentration profile in coat on (a) WC-8Co with diffusion coating from the liquid metal medium with temperature $1100^{\circ} \mathrm{C}$, duration 1 hour, (b) T15K6 with diffusion coating from the liquid metal medium with temperature $1000^{\circ} \mathrm{C}$, duration 0,5 hour.
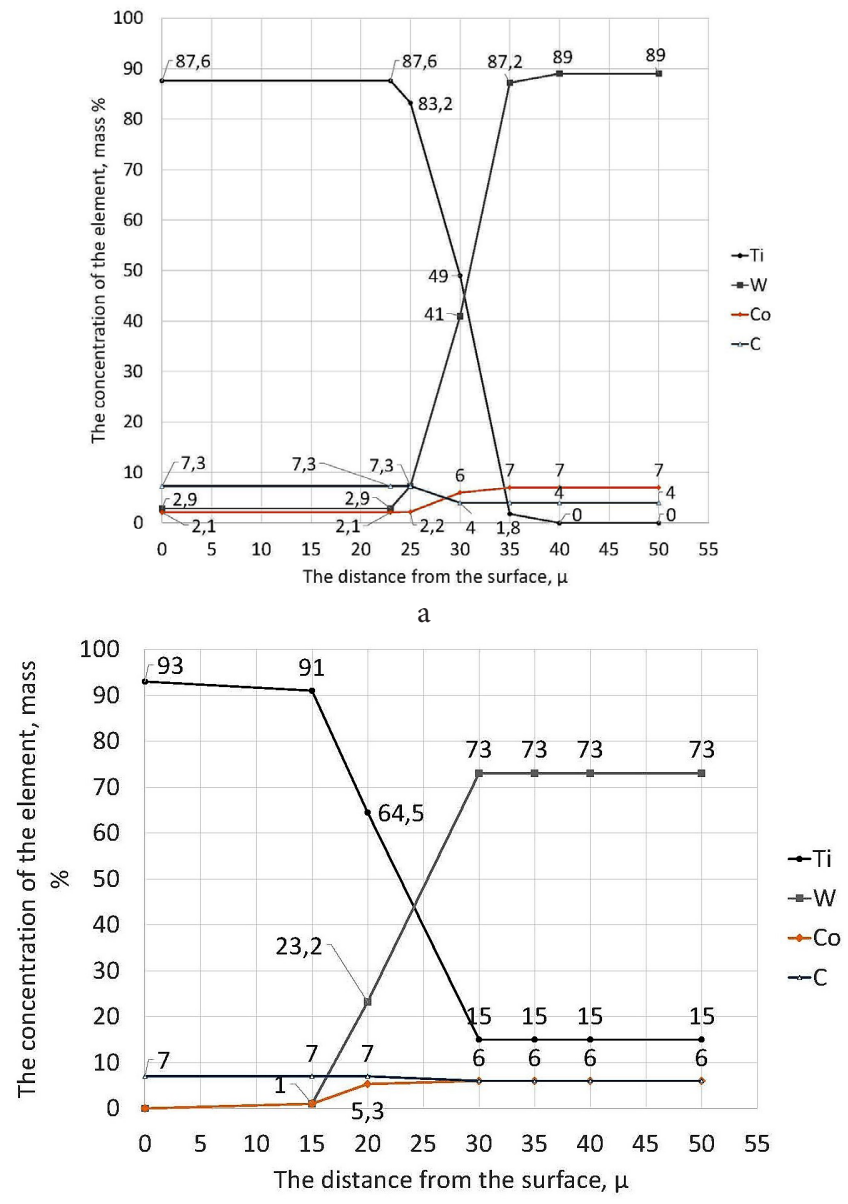

b

Рис. 2. Распределение элементов по покрытию, полученному вследствие диффузионного насыщения титаном из среды легкоплавких жидкометаллических растворов, сплавов: (a) ВК8, температура нанесения покрытия $1100^{\circ} \mathrm{C}$, длительностью 1 час, (b) Т15К6, температура нанесения покрытия $1000^{\circ} \mathrm{C}$, длительностью 30 мин.

Fig. 2. The concentration profile in coat on (a) WC-8Co with diffusion coating from the liquid metal medium with temperature $1100^{\circ} \mathrm{C}$, duration 1 hour, (b) T15K6 with diffusion coating from the liquid metal medium with temperature $1000^{\circ} \mathrm{C}$, duration 0,5 hour. 


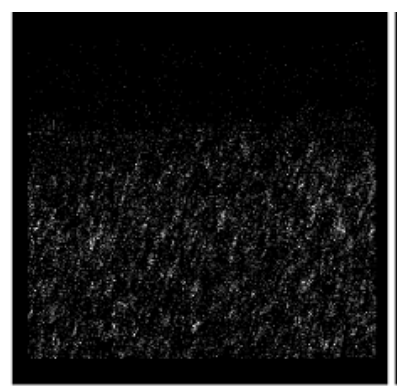

CoKa1

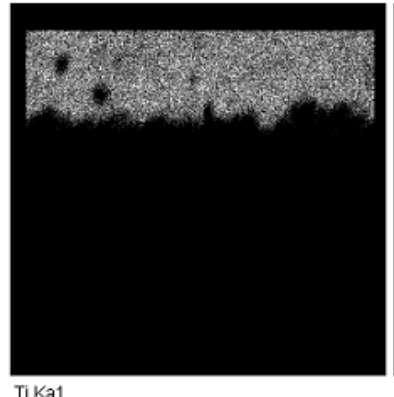

Ti Ka1

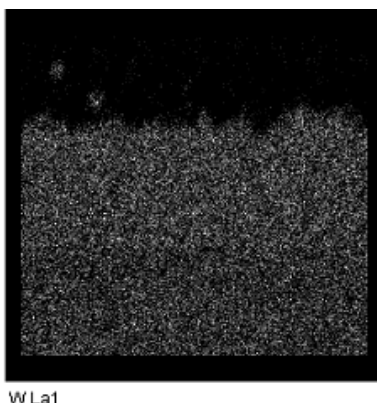

WLa1

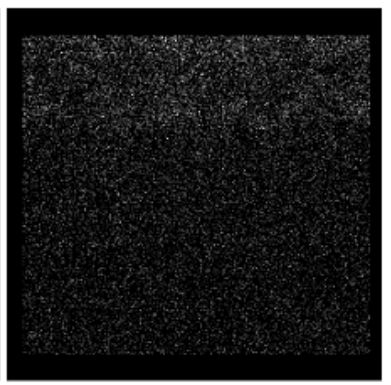

CKa1_2
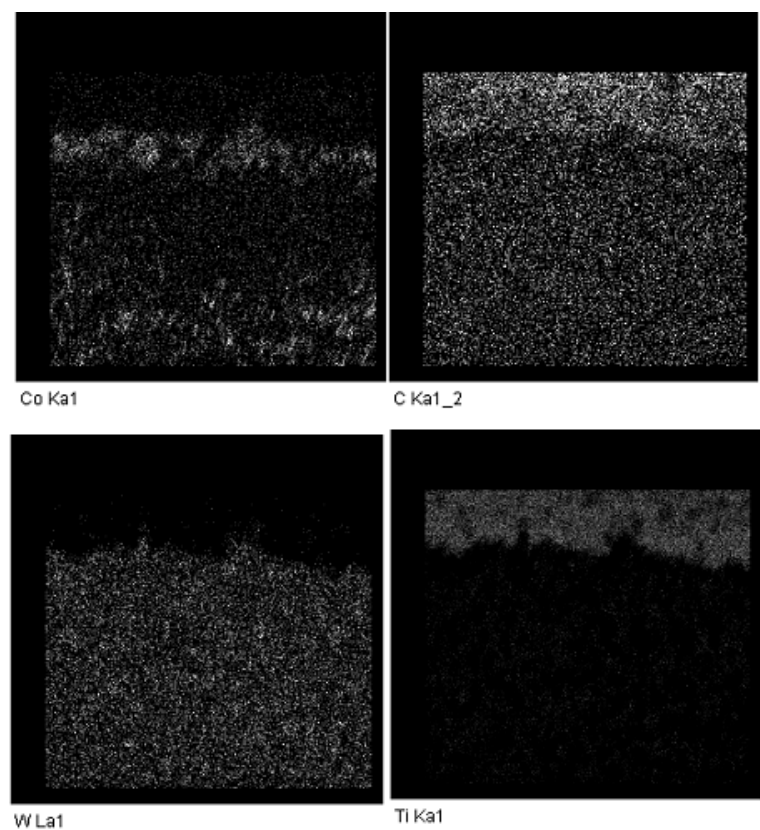

Рис. 3. Карта распределения химических элементов в покрытии на твердых сплавах: (а) ВК8, температура нанесения покрытия $1100^{\circ} \mathrm{C}$, длительностью 1 час, (b) Т15К6, температура нанесения покрытия $1000^{\circ} \mathrm{C}$, длительностью 30 мин.

Fig. 3. The map of the dealing of chemical elements in the coating (a) WC-8Co with diffusion coating from the liquid metal medium with temperature $1100^{\circ} \mathrm{C}$, duration 1 hour, (b) T15K6 with diffusion coating from the liquid metal medium with temperature $1000^{\circ} \mathrm{C}$, duration 0,5 hour.

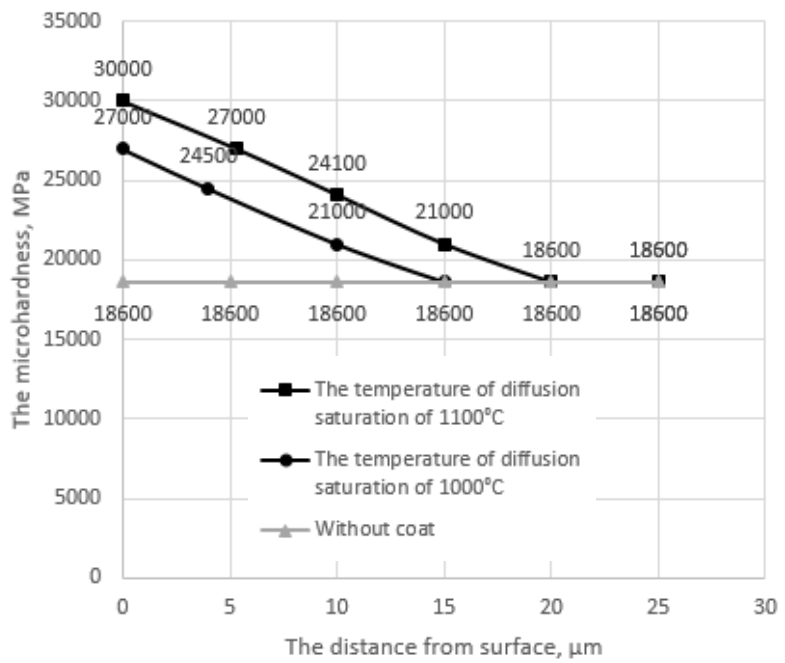

a

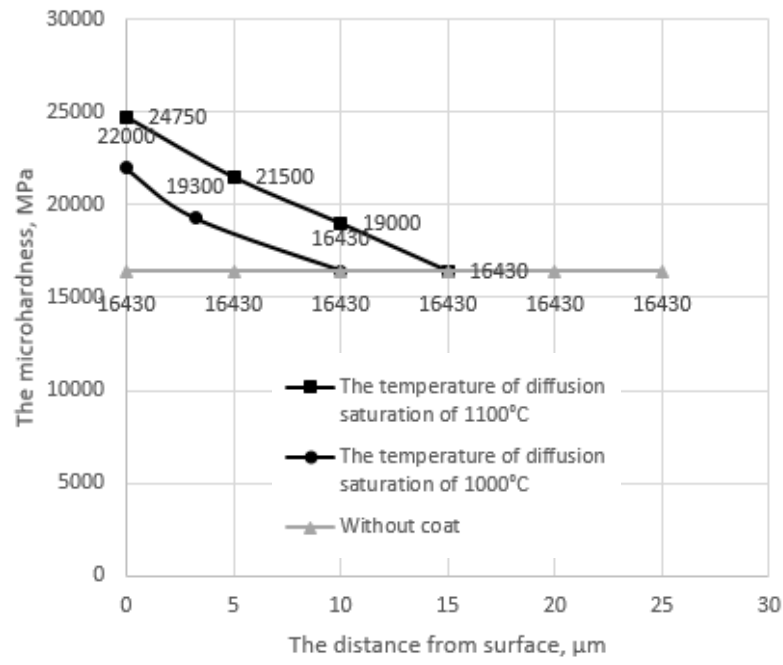

b

Рис. 4. Микротвердость покрытия и переходной зоны твердосплавных пластин, подвергнутых диффузионному насыщению титаном из среды легкоплавких жидкометаллических растворов при температурах $1000^{\circ} \mathrm{C}$ и $1100^{\circ} \mathrm{C}$ : (a) T15K6, (b) BК8.

Fig. 4. The microhardness of coat and transition zone of carbide-tipped plates, have diffusion titanium coats from liquid metal medium solutions with temperature $1000^{\circ} \mathrm{C}$ and $1100^{\circ} \mathrm{C}$ : (a) T15K6 (b) WC-8Co.

кометаллических растворов на сплавах групп ТК и ВК формируются на основе карбидов титана ТіС с незначительным содержанием элементов материала-основы кобальта и вольфрама. При этом, кобальт оттесняется в переходную зону покрытия.

Однако, в сформировавшемся таким образом покрытии наблюдается значительная неравномерность распределения углерода в нем. При этом, в приповерхностных слоях покрытия образуются зоны с повышенным содержанием углерода, что вызывает охрупчивание покрытия.
Для исключения этого явления покрытия (покрытые изделия), подвергают процессу старения, который осуществляют путем нагрева покрытого изделия до температуры $300-800^{\circ} \mathrm{C}$ с последующей выдержкой при этой температуре в течение 60-120 мин. Данная обработка обеспечивает перераспределение углерода по покрытию, что обеспечивает дополнительное выделение второй дисперсной фазы в виде карбида титана. Эти процессы приводят к повышению твердости покрытия при одновременном снижении его хрупкости [11]. 


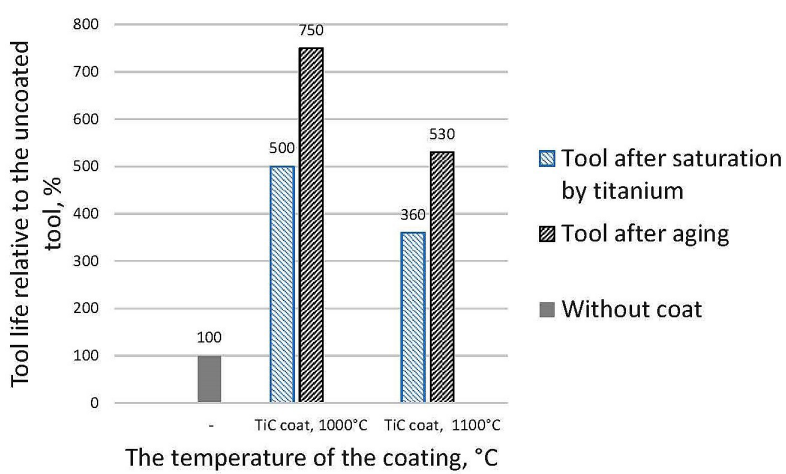

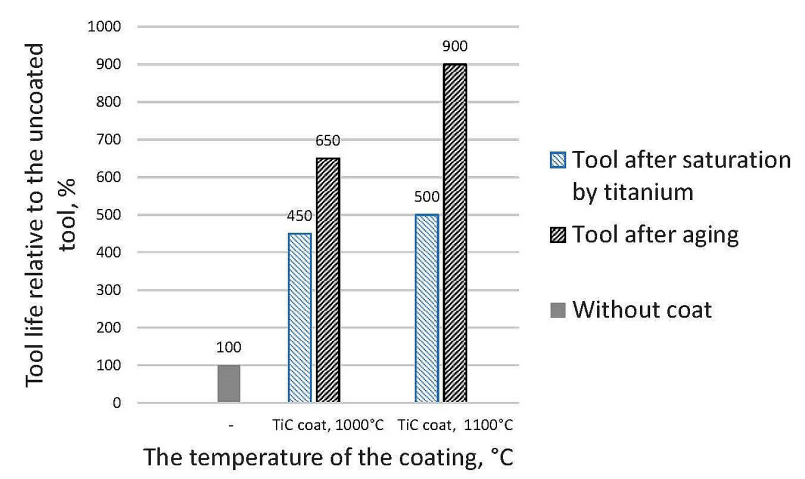

$\mathrm{b}$

Рис. 5. Зависимость стойкости твердосплавного инструмента, имеющего диффузионное титановое покрытие, подвергнутого старению, от режимов нанесения покрытия: (а) Т15К6, (b) ВК8.

Fig. 5. The relative of the carbide-tipped tool life with diffusion titanium coating and following aging to the mode of coating process: (a) T15K6 plates (b) WC-8Co.

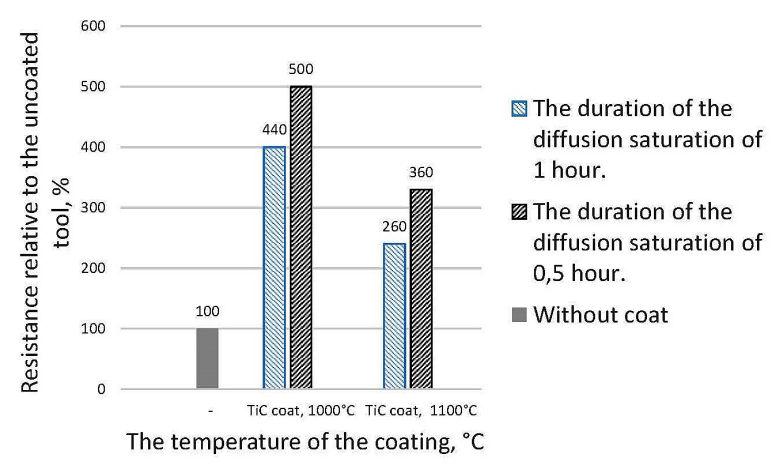

a

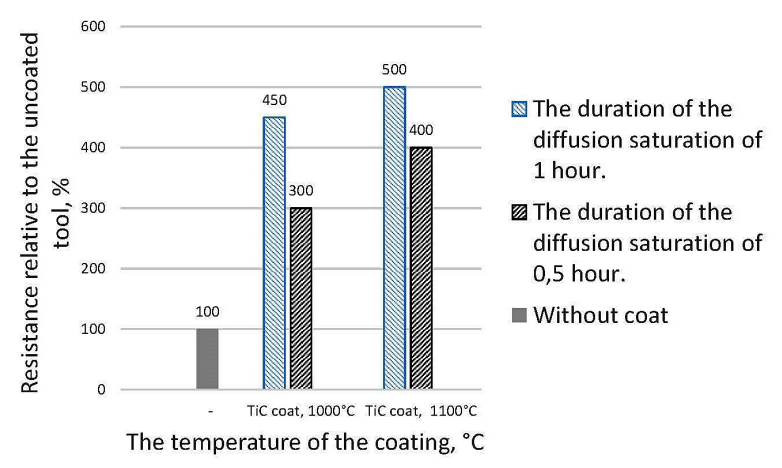

$\mathrm{b}$

Рис. 6. Зависимость стойкости режущих пластин от температуры и длительности нанесения покрытия: (a) Т15К6, (b) ВК8.

Fig. 6. The depending of the tool life of carbide-tipped tool of mode of coat applying: (a) T15K6 plates, (b) WC-8Co plates.

\section{2. Эксплуатационные свойства диффузионно- титанированного режущего инструмента}

Исследование по оценке влияния диффузионного титанирования из среды легкоплавких жидкометаллических растворов на эксплуатационные свойства (стойкость) режущего инструмента проводились на сплавах типа ТК и ВК. Покрытия наносились по различным технологическим режимам, при этом варьировались температура диффузионного насыщения и время выдержки пластин в расплаве, а также оценивалось влияние термической обработки - «старения», проводимой после диффузионного титанирования.

Диффузионное насыщение проходило при температурах $1000-1100^{\circ} \mathrm{C}$, длительностью 30-60 минут. Выбор данного диапазона температур обусловлен тем, что во время нанесения покрытий при температурах ниже $1000^{\circ} \mathrm{C}$, оно содержит большое количество карбида титана, обладающего высокой твердостью и хрупкостью, что отрицательно сказывается на стойкости инструмента. При нанесении покрытия при температурах $1000-1100^{\circ} \mathrm{C}$ в покрытии увеличивается содержание $\alpha-\mathrm{Ti}$, выполняющего роль связки и увеличивающий вязкость покрытия, что влечет за собой увеличение стойкости инструмента [1]. Так, при нанесении покрытия на режущий инструмент при температуре $1000^{\circ} \mathrm{C}$ и выдержкой 30 минут, изготовленный из твердого сплава марки
Т15К6, его стойкость увеличивается в 5 раз (рис. 6а). Аналогичное повышение стойкости в 5 раз наблюдается так же и при нанесении покрытия на режущий инструмент, изготовленный из твердого сплава ВК8, но уже при температуре $1100^{\circ} \mathrm{C}$ и длительности выдержки 60 минут (рис. 6b). Стойкость непокрытых пластин была принята за $100 \%$.

После нанесения покрытия, инструмент был подвергнут процессу старения в интервале температур от 300 до $800^{\circ} \mathrm{C}$ в течении 60 минут. Вследствие старения инструмента, имеющего диффузионное титановое покрытие, происходит увеличение его периода стойкости. Увеличение стойкости относительно непокрытого инструмента составляет более чем в 7 раз. За 100\% принималась стойкость резца без покрытия (рис. 5). Зависимость стойкости инструмента после старения от режимов нанесения покрытия представлена на рис. 5. Подробно влияние термической обработки титанированного инструмента рассмотрено в предыдущих работах [11].

\section{4. Выводы}

1. Нанесение диффузионных титановых покрытий путем диффузионной металлизации из среды легкоплавких жидкометаллических растворов на твердые сплавы приводит к формированию на их поверхности двухслойных покрытий на базе карбида титана. 
2. Диффузионное насыщение титаном твердых сплавов типа ТК и ВК оказывает значительное влияние на свойства их поверхностных слоев за счет формирования покрытия на базе карбида титана ТiC. При этом, микротвердость на поверхности твердого сплава типа ТК составляет до $30000 \mathrm{MПа,} \mathrm{для} \mathrm{сплавов} \mathrm{типа} \mathrm{ВК} \mathrm{-}$ до 24750 МПа.

3. Вследствие диффузионного титанирования твердых сплавов типа ТК концентрация титана в поверхностных слоях покрываемого изделия составляет 93\% (масс). Для сплавов ВК концентрация титана составляет $87,6 \%$ (масс).

4. Переходный слой характеризуется примерно равной концентрацией титана и вольфрама на уровне 20 - 25\%. При этом, данный слой имеет меньшую микротвердость, чем микротвердость поверхностного слоя. Это связано с увеличением концентрации карбида вольфрама в данном слое, обладающего меньшей твердостью.

5. Элементный состав покрываемого твердого сплава оказывает значительное влияние на кинетику формирования покрытий. Так, наиболее интенсивный рост покрытий, наибольшая величина переходной зоны, а также твердость покрытий наблюдается на твердых сплавах с меньшей концентрацией кобальта.

6. Нанесение диффузионных титановых покрытий на изначально непокрытый режущий инструмент из сплавов типа ВК и ТК, приводит к повышению их стойкости до 5 раз, а включение в заключительный этап технологического процесса термической обработки старения способствует повышению стойкости в 7 раз.

\section{Литература/References}

1. A.G. Sokolov, V.V. Iosifov, A.G. Shirtladze, The technologies of formation of the required mechanical and physical-chemical properties of surfaces (coating engineering): a textbook for students, masters and postgraduates of the direction «Design and technological ensuring of engineering industries». Krasnodar, «Publishing House - South». 2016. 212p. (in Russian) [А.Г. Соколов, В.В. Иосифов, А.Г. Схиртладзе, Технологии формирования требуемых механических и физико-химических свойств поверхности изделий (покрытия в машиностроении): учебное пособие для студентов, магистров и аспирантов направления «Конструкторско-технологическое обеспечение машиностроительных производств». Краснодар, Издательский Дом - Юг. 2016. 212c.]

2. S.N. Grigor'ev. The methods of increasing the life of cutting tools: textbook for students of technical colleges. M.: Mechanical Engineering. 2011. 368p. (in Russian) [C.Н. Григорьев, Методы повышения стойкости режущего инструмента: учебник для студентов втузов. - М.: Машиностроение. 2011. 368c.]
3. Sokolov A. G., Bobylyov, E. E. Obrabotka metallov. Metal working and material science. № 2 (71), p. 59-69. (2016) (in Russian) [Соколов А.Г., Бобылёв Э.Э. Обработка металлов (технология, оборудование, инструменты). № 2 (71), c. 59 - 69. (2016)]

4. Patent RF № 2451108, 20.05.2012. (in Russian) [Патент РФ № 2451108, 20.05.2012.]

5. Sokolov A.G., Artem'ev V.P. The increase of efficiency of the tool because of the methods of the diffusion metallization. Rostov-on-Don, SFEDU. 2006. 228 p. (in Russian) [Соколов А.Г., Артемьев В.П., Повышение работоспособности инструмента методами диффузионной металлизации. Ростов-на-Дону, СКНЦ ВШ. 2006. 228 c.]

6. Patent RF № 2521187, 27.06.2014. (in Russian) [Патент РФ № 2521187, 27.06.2014.]

7. Kiparisov S.S., Levinskij Ju. V., Petrov A.P. The titanium carbide: preparation, properties, application. M.: Metallurgy. 1987. 216 p. (in Russian) [Кипарисов С. С., Левинский Ю.В., Петров А.П. Карбид титана: получение, свойства, применение. М.: Металлургия. 1987. 216 c.]

8. Sokolov A.G. Razrabotka teoreticheskih i tehnologicheskih osnov povyshenija stojkosti rezhushhego i shtampovogo instrumenta za schet diffuzionnoj metallizacii iz sredy legkoplavkih zhidkometallicheskih rastvorov: Dissertacija na soiskanie stepeni doktora tehnicheskih nauk. Krasnodar. (2008) 369 c. (in Russian) [Соколов А.Г. Разработка теоретических и технологических основ повышения стойкости режущего и штампового инструмента за счет диффузионной металлизации из среды легкоплавких жидкометаллических растворов: Дисс. д-ра техн. наук. Краснодар. 2008. 369 с.]

9. Panov V.S., Chuvilin A. M. The technology and properties of sintered hard alloys and products from them. The textbook for high school. M: MISIS. 2001. 428p. (in Russian) [Панов В.С., Чувилин А.М. Технология и свойства спеченных твердых сплавов и изделий из них. Учебное пособие для вузов. М.: МИСИС. 2001.428 c.]

10. Sokolov A.G., Bobylyov E.E. Materials of 17-th international scientific-practical conference «technologies of hardening, coating and repair: theory and practice». Saint-Petersburg. 2015. c. 446-451. (in Russian) [Соколов А.Г., Бобылёв Э.Э. Материалы 17-й международной научно-практической конференции «Технологии упрочнения, нанесения покрытий и ремонта: теория и практика». Санкт-Петербург. 2015. c. $446-451$.]

11. Sokolov A.G., Bobyljov E.E., Aref'eva S.A. Journal perspektivnie materialy. № 12, p.45-51. (2016). (in Russian) [Соколов А. Г., Бобылёв Э.Э., Арефьева С. А. Перспективные материалы. № 12, p.45-51. (2016).] 